\title{
Bones, stones and androgen deprivation therapy
}

\author{
Miguel Ángel Arrabal-Polo, ${ }^{1}$ María del Carmen Cano-García, ${ }^{1}$ Miguel Arrabal-Martín ${ }^{2}$ \\ ${ }^{1}$ Urology Department, La Inmaculada Hospital, Huércal-Overa, Almería; ${ }^{2}$ Urology Department, University Hospital of \\ Granada, Institute IBS Granada, Granada; Spain
}

\section{Dear Editor}

It is well known that patients with recurrent calcium nephrolithiasis present bone mineral density loss manifesting as osteopenia or osteoporosis in the lumbar spine and/or hip. ${ }^{1}$ Moreover, it has been observed that in patients with calcium stones and idiopathic hypercalciuria, higher levels of fasting calcium/creatinine increase the possibility of osteopenia, therefore there is a risk factor for bone mineral density loss. ${ }^{2}$ Some markers that are increased in patients with bone mineral density loss and recurrent calcium nephrolithiasis, such as alkaline phosphatase, osteocalcine, $\beta$-crosslaps, calciuria and fasting calcium/creatinine in urine, are useful in the diagnosis, together with image tests (bone densitometry, abdominal CT) and follow-up after initiation of treatment. ${ }^{2}$ Although no single mechanism has as yet been identified to explain bone mineral density in patients with recurrent calcium stones, inflammatory and hormonal factors could be involved in the pathophysiology. ${ }^{3}$

It has been observed that patients with prostate cancer who are given hormonal therapy to block androgen production demonstrate an increase in bone mineral density loss, which, as would be expected, results in osteoporosis and the attendant risk of bone fracture. ${ }^{4}$ Given that the rate of bone loss appears to

\footnotetext{
Address for correspondence:

Miguel Ángel Arrabal-Polo,

Doctor Virgili Str., 9, bajo C. Huercal Overa,

Postal zip: 04600, Almería, Spain

Tel.: +34628837188, E-mail: arrabalp@ono.com.

Received: 11-09-2015, Accepted: 28-09-2015
}

be maximal in the first year of treatment, ${ }^{4}$ a rational approach would be for these patients to undergo pre-therapy densitometry as well as to be checked for metabolic markers, such as calciuria and fasting calcium/creatinine. The most common treatment for prevention of osteoporosis in patients with androgen deprivation therapy is calcium plus vitamin $\mathrm{D}$ together with an antiresortive drug. ${ }^{5}$ However, based on our knowledge of the relationship between osteoporosis and recurrent calcium stones, it appears advisable to study each patient's metabolic profile before initiating treatment with calcium plus vitamin D in order to avoid an increase in the risk of calcium stones. In a preliminary study, we observed in 10 patients with prostate cancer a $15 \%$ increase in the incidence of calcium stones after two years of androgen deprivation therapy; the hypothesis is that this outcome could have been produced by the effect of the specific treatment on bone, which induces osteoporosis and secondary fasting hypercalciuria. Since to date no studies have analyzed the relation between androgen deprivation therapy, bone and calcium stones, it is our belief that this aspect of the therapy should be carefully examined to elucidate whether the above observation is valid.

\section{CONFLICT OF INTEREST}

The authors declare no conflict of interest and no funding.

\section{REFERENCES}

1. Arrabal-Polo MA, del Carmen Cano-García M, Canales BK, Arrabal-Martín M, 2014 Calcium nephrolithiasis 
and bone demineralization: pathophysiology, diagnosis, and medical management. Curr Opin Urol 24: 633-638.

2. Letavernier E, Traxer O, Daudon M, et al, 2011 Determinants of osteopenia in male renal-stone-disease patients with idiopathic hypercalciuria. Clin J Am Soc Nephrol 6: 1149-1154.

3. Heilberg IP, Weisinger JR, 2006 Bone disease in idio- pathic hypercalciuria. Curr Opin Nephrol Hypertens 15: 394-402.

4. Allan CA, Collins VR, Frydenberg M, McLachlan RI, Matthiesson KL, 2014 Androgen deprivation therapy complications. Endocr Relat Cancer 21: T119-129.

5. Nguyen PL, Alibhai SM, Basaria S, et al, 2015 Adverse Effects of Androgen Deprivation Therapy and Strategies to Mitigate Them. Eur Urol 67: 825-836. 